\title{
TRACE METAL LEVELS OF THE ODAW RIVER SEDIMENTS AT THE AGBOGBLOSHIE E-WASTE RECYCLING SITE
}

\author{
M. A. Chama ${ }^{1}$, E. F. Amankwa ${ }^{2}$ and M. Oteng-Ababio ${ }^{2}$ \\ ${ }^{l}$ Department of Chemistry, University of Ghana, Legon, Accra \\ *Corresponding author: E-mail: machama@ug.edu.gh/antichama@yahoo.com \\ ${ }^{2}$ Department of Geography and Resource Development, University of Ghana, Legon, Accra \\ E-mail: ebenchief@yahoo.com; moababio@ug.edu.gh
}

\begin{abstract}
The lack of appropriate infrastructure and legislation regarding the proper way of handling $e$ wastes has encouraged informal recycling as in the case of the Agbogbloshie e-waste site. The burning and dumping of these wastes at the bank of the Odaw River eventually end up in the river. To ascertain the level of trace metal contamination in the Odaw River, 15 sediment samples collected from five different locations were analyzed for their trace metals. The locations were chosen to represent areas near to heavy e-waste activities and areas with no apparent ewaste activities, and analysis carried out using Atomic Absorption Spectrophotometry. The results indicated that mean concentrations of the trace metals $(\mathrm{Cu}, \mathrm{Cd}, \mathrm{Pb}, \mathrm{Fe}, \mathrm{Cr}$ and $\mathrm{Ni})$ were highest at locations near burning and dumping sites (L1 and $L 2$ respectively). This was attributed to the result of e-waste activities and the configuration of the river. With the exception of $\mathrm{Cu}$ and $\mathrm{Cd}$ at $\mathrm{L1}$, the rest of the metals were below the recommended Canadian interim sediment quality guideline (ISQG) while none was above the Probable Effect Level (PEL), an indication that the levels of trace metal contamination were below the concentration at which frequent adverse effects are expected to occur. The results have confirmed that e-waste recycling activities along the banks of the Odaw River contribute to the contamination of the river.
\end{abstract}

Keywords: E-waste, sediment, metal, contamination, recycling

\section{INTRODUCTION}

The rapid innovation and use of electronic and electrical equipment (EEE) globally has increased its obsolescence rate leading to an increasing e-waste generation (Oteng-Ababio, 2010). E-waste is a generic term for the end-of- life of EEE (ie computers, televisions, cell phones, home appliances) that is of no value to the owner. About 6 million tonnes of e-waste were generated globally in 1998 (Arensmann, 2000 ), increasing to $20-50 \mathrm{~m}$ tonnes in 2005 , which is about $5 \%$ of municipal waste (OECD, 


\section{Chama et al.}

2008). Ghana has witnessed phenomenal growth in the use of new technologies in national development. The penetration rate of computer has increased from 128,000 units in 2005 to $1.9 \mathrm{~m}$ units in 2009 (Amoyaw-Osei et al., 2011). The number of obsolete EEE amounted to 280,000 tonnes in 2009 , out of which $57 \%$ went to repairs, $8 \%$ to storage and $34 \%$ directly to recycling, with about $5.7 \mathrm{~m}$ mobile phones becoming obsolete yearly. According to UNEP (2005), 75\% of second-hand computers in shipments are unusable. Yet, most receiving countries including Ghana are bereft of enforceable legislation and e-waste management systems. The lack of efficient system has made Agbogbloshie achieved notoriety of being the e-waste recycling hub in Ghana, with some health and environmental challenges due to the manual dismantling and burning, which release toxic substances into the atmosphere, soils and water bodies (Brigden et al., 2005; Pinto, 2008).

Thus, some ecological balances may be altered leading to possible contamination of food sources. The Odaw River in the Agbogbloshie serves as a receptacle to most remnants of the recycling activities. Earlier scholarships (Brigden et al., 2008; Asante et al., 2012) at the site have indicated the presence of trace metals (Otsuka et al., 2012). The accumulation of metals in the aquatic ecosystem has direct consequence to human and to the ecosystem. Interest in metals like $\mathrm{Zn}$ and $\mathrm{Se}$, which are required for metabolic activities in living organisms lies in the narrow "window" between their essentiality and toxicity (Fatoki et al., 2002), thus necessitating their regular monitoring (Merian and Clarkson, 1991). In most instances, their sources in the aquatic ecosystem are mainly from anthropogenic influences rather than natural enrichment of the sediment (Binning and Baird, 2001).

Despite its strategic location, there have not been any comprehensive studies on the levels of sediment contamination of the Odaw River by the recycling activities. Hence, the need to determine the level of trace metals resulting from the filths discharged into the river including both solid waste and excreta. The detection and determination of these trace metals in the aquatic ecosystem is of considerable importance for monitoring and controlling the pathways by which they reach the hydrosphere. As a result of extensive pollution, the river is virtually dead. There is hardly aquatic life in it. While the city authorities battle with its costly dredging, the scrap dealers, traders and squatters have compounded its woes by dumping all manner of waste into the river. This study reports the levels of trace metals in sediments at various locations of the river. It aims at ascertaining the extent of contamination and the potential environmental pollution. The catchment especially the Agbogbloshie supports a rapidly growing population and there are concerns regarding the quality of vegetables cultivated along the banks of the river.

\section{MATERIALS AND METHODS}

The Study Area

The study area is situated in the capital city of Ghana, Accra. It is a triangular land of about $1.5 \mathrm{~km}^{2}$ in area, bounded by the Abossey Okai road, the Odaw River (in the upper reaches of the Korle lagoon) and the Agbogbloshie drain which is less than a kilometre from the Central Business District (CBD) (Fig. 1).

The area is under the Ashiedu keteke sub-metro with an estimated population of about 80,000 (Amankwaa, 2013; Oteng-Ababio and Amankwaa, 2014). It has $50.01 \%$ of the population being males and $49.99 \%$ females, with a population density of about 2,500 persons per hectare (Housing the Masses, 2010).

\section{Sampling}

The samples for analysis were all sediments obtained from five sampling sites in 2012. The sampling sites were chosen to ensure that the variation in the extent of river contamination with respect to e-waste recycling was covered. Samples were taken from locations L1 near ewaste burning site A, L2 near e-waste dumping 


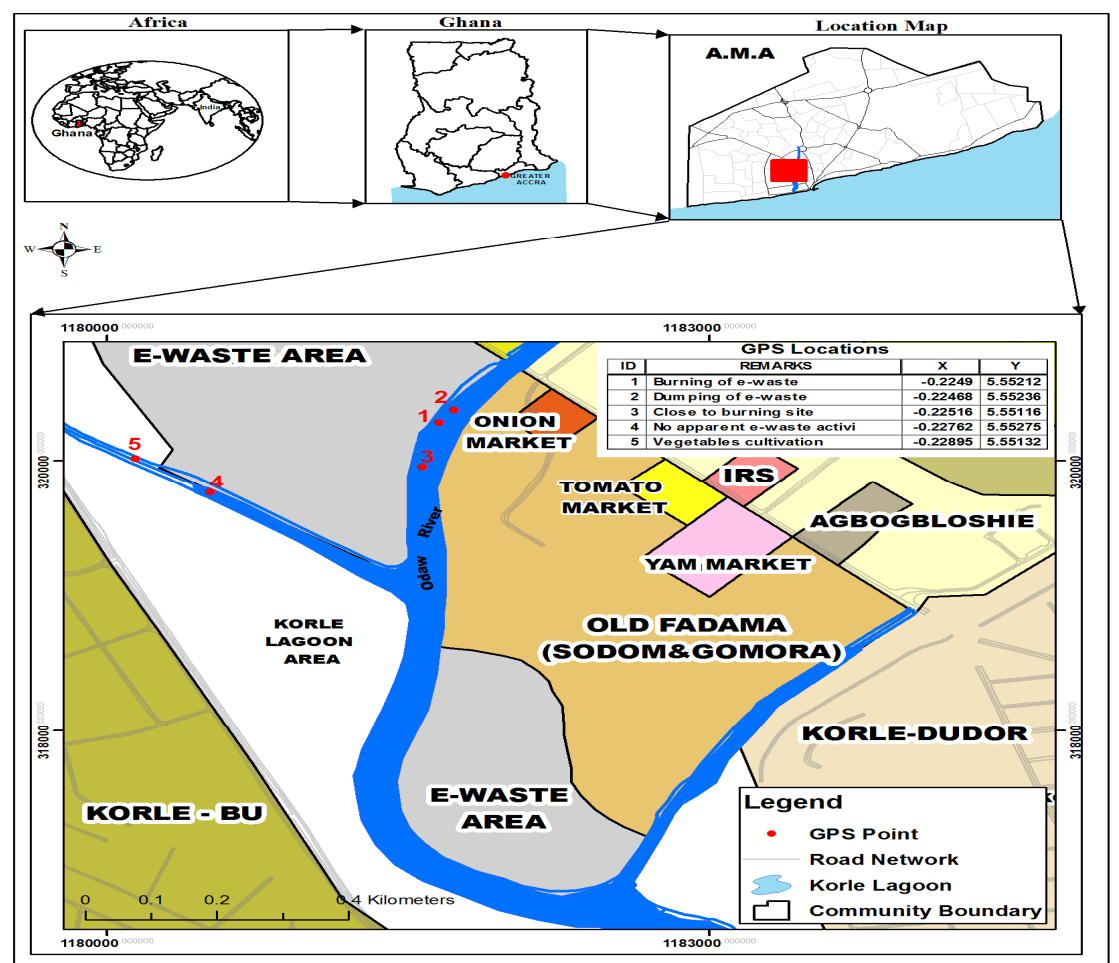

Fig. 1: Map of study area showing sampling points

site, L3 near e-waste burning site B, L4 where there is no apparent e-waste activity, and L5 near vegetable cultivation area (Fig. 1). The positions of the sampling points were determined by the use of a handheld Garmin e-Trex Global Positioning System (GPS) and the coordinates recorded at an accuracy level of three meters.

Sediment samples were collected into precleaned polyethylene bags with an augur and a hand shovel. The shovel was used to scoop sediment from 10 to $15 \mathrm{~cm}$ depth with hand gloves into pre-cleaned well labeled polyethylene bags and transported in an ice cooler. A total of 15 samples were collected for the study made of three samples from each five sampling locations.

\section{Sample preparation}

Each sediment sample was air-dried in a clean environment. Other organic debris such as shells, wood etc were picked from the samples with hand gloves on. The samples were disaggregated manually with agate mortar and pestle, sieved through $0.5 \mathrm{~mm}$ sieve, homogenized and subjected to digestion. The samples were microwave digested following Milestone application protocol (Milestone Application note, 1996). All the reagents used were of analytical grade. About 1.5g of homogenized sediment sample was weighed into labeled acid cleaned polytetrafluoroethylene (PTEF) Teflon vessels (bombs) of ETHOS 900 Labstation microwave digester. Volumes of $6 \mathrm{ml}$ conc. $\mathrm{HNO}_{3}(65 \%)$, $3 \mathrm{ml} \mathrm{HCl} \mathrm{(37 \% ),} \mathrm{and} 0.25 \mathrm{ml} \mathrm{H}_{2} \mathrm{O}_{2}(30 \%)$ were added to each vessel containing the homoge- 
nized sediment samples in a fume chamber. The Teflon vessels were swirled gently to mix the content and loaded vertically onto the microwave carousel with the vessel cap tightly screwed. The complete assembly was fitted into the ETHOS 900 Milestone Labstation microwave digester and irradiated for 21 minutes using the following operating conditions in

Table 1. After digestion, samples were cooled in a water bath for 20 minutes to reduce temperature and internal pressure built up within the vessel as well as to allow volatilized materials to re-solubilise. The digestate was quantitatively transferred into a $20 \mathrm{ml}$ volumetric flask and made to the mark using distilled water. Reagent blanks and certified reference material were also prepared similarly.

\section{Sample Analysis}

The digested sediment samples were analyzed by both classical and automated instrumentation method as appropriated in standard methods $(A P H, 1998)$. The samples were analyzed with VARIAN AA240FS Atomic Absorption Spectrophotometer (AAS) using acetylene gas as fuel and compressed air as oxidant. Each sediment sample was analyzed in triplicate.

\section{Quality control}

For quality assurance and quality control purposes, reagent blanks and certified reference material (IAEA, 2011) were analysed with each batch of samples to ensure accuracy and to detect any contamination during the analytical procedure. Spiked samples were also analysed and recovery measured. All reagents used were of analytical grade and instrument precalibrated appropriately prior to measurement. Triplicate analysis was carried out for each determination to ascertain reproducibility.

\section{RESULTS AND DISCUSSION}

Percentage recoveries of spiked samples ranged between 79.85-97.65\% and the certified reference materials analysed were in agreement with certified values. The precision was found to be within $\pm 5 \%$ for all elements which validate the experimental procedure used for the chemical analysis.

The results as indicated in Table 2 show that metal concentrations in the sediments ranged from 7.58-43.44 $\mu \mathrm{g} / \mathrm{g}$ for copper $(\mathrm{Cu}), 0.07$ $0.62 \mu \mathrm{g} / \mathrm{g}$ for cadmium $(\mathrm{Cd}), 10.60-32.66 \mu \mathrm{g} / \mathrm{g}$ for lead $(\mathrm{Pb}), 12.85-13.42 \mu \mathrm{g} / \mathrm{g}$ for iron $(\mathrm{Fe})$, $1.49-5.46 \mu \mathrm{g} / \mathrm{g}$ for chromium $(\mathrm{Cr})$, and 2.23$5.89 \mu \mathrm{g} / \mathrm{g}$ for nickel $(\mathrm{Ni})$. The relatively small standard deviations (0.03-1.8) of the heavy metal concentrations of sediments suggest that the sediments are homogeneous in terms of heavy metal distribution.

Almost all the mean concentrations of metals of L1 (near burning site) sediments were the highest with the exception of mean concentrations for $\mathrm{Fe}$ and $\mathrm{Cr}$. Correspondingly, all but $\mathrm{Pb}$ had the lowest mean concentrations of metals for L5 (the farthest point from the actual burning sites and closer to the vegetable cultivation area) sediments. $\mathrm{Cu}$ and $\mathrm{Pb}$ were the dominant

Table 1: Microwave digestion program for sediment samples

\begin{tabular}{llllll}
\hline Step & Time & Power & Pressure & Temp 1 & Temp 2 \\
\hline $\mathbf{1}$ & $5 \mathrm{~min}$ & 250 & 100 & 400 & 500 \\
$\mathbf{2}$ & $1 \mathrm{~min}$ & 0 & 100 & 400 & 500 \\
$\mathbf{3}$ & $10 \mathrm{~min}$ & 250 & 100 & 400 & 500 \\
$\mathbf{4}$ & $5 \mathrm{~min}$ & 450 & 100 & 400 & 500 \\
Vent: $\mathbf{5}$ min & & & & \\
\hline
\end{tabular}


metals recorded in sediment samples from the Odaw River. Elevated levels of these metals were recorded in samples from points L1 and L2 (Fig. 2) which were near the e-waste burning and dumping sites respectively. Points L4 and $\mathrm{L} 5$ recorded significant levels of $\mathrm{Pb}$ as compared to $\mathrm{Cu}$. The higher concentrations registered may be attributed to anthropogenic sources (Binning and Baird, 2001) such as ewaste recycling activities at the catchment of the Odaw River rather than natural enrichment of the soil by geological weathering.

A one-way ANOVA at $95 \%$ confidence interval indicated that the levels of trace metals in the sediments are dependent on the site of sampling, $\mathrm{p}<0.05$.

Runoff from the e-waste burning and dumping sites which may be contaminated with trace metals directly empties into the Odaw River and this may release metals directly into the river. The Odaw River is the recipient of domestic, municipal and industrial waste from its catchment.
Sewage and other waste water constitute other discharges into the river and this might contribute to the trace metal level in the Odaw River. Most of the metals detected are known to be used in electrical and electronic devices. $\mathrm{Cd}, \mathrm{Ni}$ and $\mathrm{Pb}$ form components of batteries used in cordless and wireless telephones, cameras and lead-acid accumulators. $\mathrm{Pb}$ together with $\mathrm{Cd}$ is also used as stabilizers in PVC materials used in the coating on of wires and cables which may also be made of copper (Matthews, 1996).

Significant levels of $\mathrm{Ni}$ and $\mathrm{Cr}$ were also recorded with sampling points L1 and L2 registering the highest levels with L5 having the least.

The higher concentrations of trace metals at L1 and L2 (near the burning and dumping sites) which also coincides with where the river bends (Fig. 1) is also indicative of the fact that the configuration of the river might have contributed to high sediment deposition and metal concentrations. The upstream section of the Odaw River which drains most industrialized and municipal areas in the catchment might

Table 2: Mean concentration of metals in sediments of the Odaw River $(\mu \mathrm{g} / \mathrm{g})$

\begin{tabular}{lccccccc}
\hline Metal & \multicolumn{5}{c}{ Sampling Location } & \multicolumn{2}{c}{ Guidelines } \\
& $\mathrm{L} 1$ & $\mathrm{~L} 2$ & $\mathrm{~L} 3$ & $\mathrm{~L} 4$ & $\mathrm{~L} 5$ & ISQG $^{1}$ PEL $^{2}$ \\
\hline $\mathbf{C u}$ & $43.44 \pm 0.4$ & $25.64 \pm 2.5$ & $10.37 \pm 0.2$ & $8.64 \pm 0.7$ & $7.58 \pm 0.4$ & 35.7 & 197 \\
$\mathbf{C d}$ & $0.62 \pm 0.08$ & $0.45 \pm 0.07$ & $0.28 \pm 0.02$ & $0.27 \pm 0.1$ & $0.07 \pm 0.1$ & 0.6 & 3.53 \\
$\mathbf{P b}$ & $32.66 \pm 0.2$ & $23.39 \pm 1.8$ & $10.60 \pm 0.3$ & $20.79 \pm 1.5$ & $25.00 \pm 0.3$ & 35.0 & 91.3 \\
$\mathbf{F e}$ & $13.31 \pm 0.07$ & $13.42 \pm 0.2$ & $13.20 \pm 0.2$ & $13.18 \pm 0.07$ & $12.85 \pm 0.2$ & - & - \\
$\mathbf{C r}$ & $4.42 \pm 0.03$ & $5.46 \pm 0.03$ & $2.57 \pm 0.04$ & $2.59 \pm 0.08$ & $1.49 \pm 0.05$ & 37.3 & 90 \\
$\mathbf{N i}$ & $5.89 \pm 0.1$ & $4.62 \pm 0.06$ & $3.32 \pm 0.07$ & $4.07 \pm 0.08$ & $2.23 \pm 0.03$ & 18.0 & 36 \\
\hline
\end{tabular}

${ }^{1}$ ISQG-Interim Sediment Quality Guideline; ${ }^{2}$ PEL-Probable Effect Level; L1=near burning site A; L2=near dumping site; $L 3=$ near burning site $B ; L 4=$ no apparent $e$-waste activity; L5=near vegetable cultivation area. 


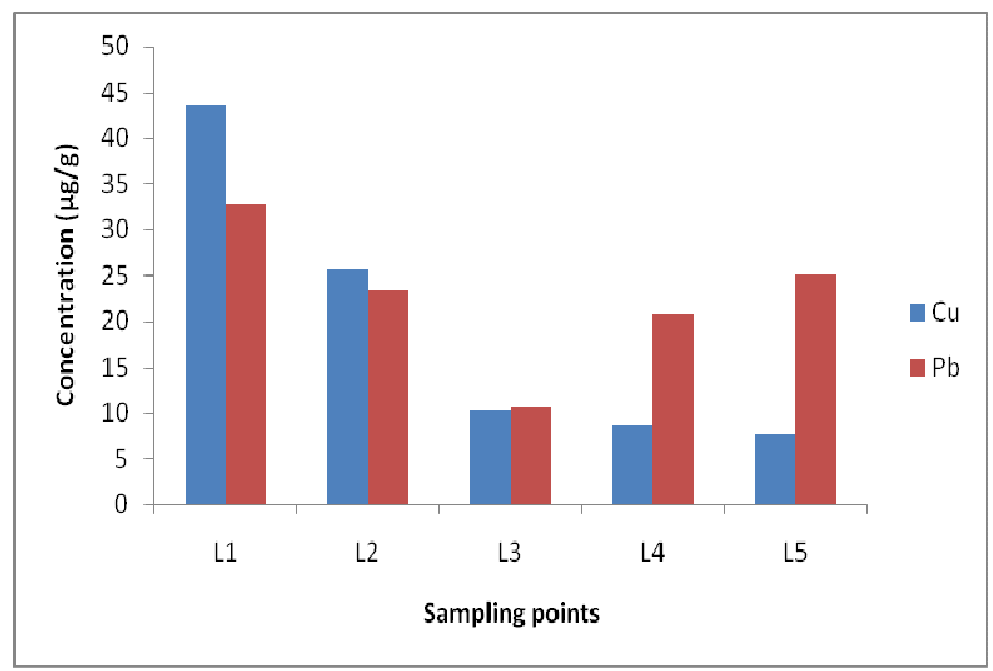

Fig. 2: Levels of $\mathrm{Cu}$ and $\mathrm{Pb}$ in Sediments

also have contributed to the elevated levels of metals in the downstream section.

Metals have the potential to be toxic to living organisms if present above threshold levels. This threshold varies between taxa and metal speciation. The potential hazard of trace metals to the aquatic environment and man depends mostly on their concentration and persistence. Persistent pollutants such as heavy metals, can remain in the environment unchanged for years and thus may pose a threat to man and other organisms. Cd is extremely toxic and the use of water high in $\mathrm{Cd}$ could cause adverse health effect to consumers such as renal disease and cancer (Fatoki et al., 2002).

The pollution levels and wide distribution reported in this study suggest that heavy metals must be considered a serious threat in the Odaw River Basin. Inadequate or no sewage treatment, e-waste menace, increasing waste from industrial and vegetable growers activities, oil spill and soil erosion are just a few of the chronic problems that the Odaw River is facing. With the exception of $\mathrm{Cu}$ and $\mathrm{Cd}$, the levels of all the metals recorded at $\mathrm{L} 1$ exceeded the $\mathrm{Ca}$ nadian interim sediment quality guideline, ISQG (Table 2) hence adverse biological effects may occur to receptors exposed to these trace metals at this point. Furthermore, none of the locations (L1-L5) showed trace metal concentration equal or greater than the Probable Effect Level (PEL), giving an indication that though there has been contamination of the Odaw River, these contaminations are below levels that can cause $50 \%$ adverse effect.

\section{CONCLUSION}

$\mathrm{Pb}, \mathrm{Cd}, \mathrm{Cu}, \mathrm{Ni}, \mathrm{Fe}$ and $\mathrm{Cr}$ levels in sediment samples from the Odaw River have been determined in this study. The results of the study indicate contamination of the Odaw River as regards trace metals. However, the levels of trace metal contamination are below the concentration at which frequent adverse effects are expected to occur and at the same time does not rule out any serious health risk to many communities in the catchment. Levels of trace metals in the sediments are an indication of man induced pollution as a result of sewage discharge into the river. The results have also con- 
firmed that e-waste recycling activities along the banks of the Odaw River contribute to the contamination of the river and suggested that these practices may lead to health risks and other environmental challenges

\section{REFERENCES}

Amankwaa, E. F. (2013). "Livelihoods in risk: exploring health and environmental implications of e-waste recycling as a livelihood strategy in Ghana", Journal of Modern African Studies 51: 551-575.

American Public Health Association, APHA., (1998). Standard method for the examination of water and wastewater (20th ed). Washington DC.

Amoyaw-Osei, Y., Opoku-Agyekum, O., Pwamang, J. A., Mueller, E., Fasko, R. and Schluep, M. (2011). Ghana e-waste country assessment. SBC e-waste Africa Project'. Accra, Ghana.

Arensman, R. (2000). "Ready for recycling". Electronic Business, 26: 108-115.

Asante, K. A., Agusa, T., Biney, C. A., Agyekum, W. A., Bello, M., Otsuka, M., Itai, T., Takahashi, S. and Tanabe, S. (2012). "Multitrace element levels and arsenic speciation in urine of e-waste recycling workers from Agbogbloshie, Accra in Ghana". Science of the Total Environment 424: 63-73.

Binning, K., Baird, D. (2001). "Survey of heavy metals in the sediments of the Swartkops River estuary, Port Elizabeth South Africa". WaterSA 27: 461-466.

Brigden, K., Labunska, I., Santillo, D. and Allsopp, M., (2005). Recycling of electronic wastes in China and India: Workplace and environmental contamination. Greenpeace Research Laboratories Technical note. Greenpeace International, The Netherlands.

Brigden, K., Labunska, I., Santillo, D., and
Johnston, P. (2008). Chemical contamination at e-waste recycling and disposal sites in Accra and Koforidua, Ghana. Report commissioned by Greenpeace International. Greenpeace Research Lab Technical Note 10/2008. Amsterdam.

Fatoki, O. S., Lujiza, N., and Ogunfowokon, A. O. (2002). "Trace metal pollution in Umtata River". WaterSA 28: 183-189.

Housing the Masses, (2010). Final report to People's Dialogue on human settlements. People's Dialogue, Ghana.

International Atomic Energy Agency (IAEA 452). (2011). Certified reference material, trace element and methyl mercury in biota. Vienna International centre, Australia. RS_IAEA_452_02.

Matthews, G., (1996). PVC: Production, properties and uses. The institute of materials, London.

Merian, E., Clarkson T.W., (1991). Metals and their compounds in the environment. Occurrence, analysis and biological relevance. $\mathrm{VCH}$, New York.

Milestone Application note, (1996). Microwave Acid digestion Cookbook. Milestone Lab Systems. Report codes 23 and 99.

OECD (Organisation for Economic Cooperation and Development) (2008). Environmental Outlook to 2030. OECD publishing, France.

Oteng-Ababio, M. (2010). "E-waste: an emerging challenge for solid waste management in Ghana". International Development Planning Review 32: 191-206.

Oteng-Ababio, M., and Amankwaa, E. F. (2014). "The e-waste conundrum: balancing evidence from the North and on-the ground developing countries realities for improved 
management". African Review of Economics and Finance 6: 181-204.

Otsuka, M., Itai, T., Asante, K. A., Muto, M., and Tanabe, S. (2012). "Trace element contamination around the e-waste recycling site at Agbogbloshie, Accra city, Ghana". Environmental Pollution and Ecotoxicology 6: 161-167.

Pinto, V. N. (2008). "E-waste hazard: Impend- ing challenge". Indian Journal of Occupational and Environmental Medicine 12: 6570 .

United Nations Environment Programme, UNEP. (2005). E-waste: the hidden side of IT equipment's manufacturing and use. Early warnings on emerging environmental threats No.5, United Nations Environment. 